\title{
Mechanical behavior of ultrafine-grained materials under combined static and dynamic loadings
}

\author{
Y.Z. Guo ${ }^{\text {a }}$ X.Y. Sun, J.G. Li, X. Yu, and Y.L. Li \\ School of Aeronautics, Northwestern Polytechnical University, Xi’an, China
}

\begin{abstract}
Ultrafine-grained (UFG) materials have extensive prospects for engineering application due to their excellent mechanical properties. However, the grain size decrease reduces their strain hardening ability and makes UFG materials more susceptible to deformation instability such as shear localization. In most cases, critical shear strain is taken as the criterion for formation of shear localization under impact loading or adiabatic shear band (ASB). Recently, some researchers found that the formation of ASB was determined only by the dynamic loading process and had nothing to do with its static loading history. They proposed for coarse-grained metals a dynamic stored energy-based criterion for ASB and verified it by some experiments. In this study, we will focus on the shear localization behavior of UFG metals such as UFG titanium and magnesium alloy AZ31. Quasi-static loading and dynamic loading will be applied on the same specimen alternately. The shear localization behavior will be analyzed and the criterion of its formation will be evaluated.
\end{abstract}

\section{Introduction}

Nanocrystalline/Ultrafine-grained (NC/UFG) materials have drawn extensive attention in the last few decades due to their superior mechanical properties, such as improved yield stress, high strength and good wear resistance (1). However, one drawback that hinders their engineering application is the decreased ductility. Many researchers have focused on this manner and made their contributions (2-4). The failure of UFG metals usually starts from necking under tension while from shear banding under compression. As in the case of dynamic loading, adiabatic shear (AS) localization is recognised as a trigger of catastrophic failure for most metals under compression (5-6). In fact, the phenomena of adiabatic shear banding (ASB) is widely encontered in industries such as metal forming, high-speed machining, balastic impact and so on (7). Whether ASB occurs or not in a material under impact depends on the competation between work hardening and thermal softening. Since the ability of strain hardening is greatly reduced or vanished for most NC/UFG materials, the propensity of ASB within these materials would be enhanced (8-9).

An important issue related to adiabatic shear localization is to build up the criterion of ASB formation. A few kinds of ctrterion have been established in the past few decades, which, however, were mainly based on the critical shear strain (6). Recently, Rittel and co-workers proposed a new point based on their experiments (10). They found that the shear localization of AM50 alloy was only determined by its dynamic loading history but had nothing to do with the fore stactic loading or thermal effect. They suggested that "dynamic mechanical energy" be a better criterion for ASB formation. In their following work,

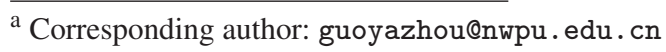

Rittel and co-workers (11) proposed a possible mechanism of ASB initiation, i.e., dynamic recrystalization. The microstructure of UFG materials are usually unstable compared to their coarse grain (CG) conterparts, thus it is reasonable to deduce that the ctriterion by Rittel et al. would be suitable for UFG materials. However, we did not find any published work on this aspect.

In this paper, combined static and dynamic compressive testing are carried out on two kinds of materials, ie. UFG titanium and fine-grained AZ31 magnesium alloy. The experimental results of CG AZ31 alloy are also given for comparison. The conditions of ASB formation are analyzed and the criterions are discussed. The results of this work would be instructive in understanding the nature of ASB.

\section{Experiments}

\subsection{Materials}

Two kinds of materials are employed in this work, ie. pure titanium and AZ31 magnesium alloy. The as-received Ti is a grade 2 commercial purity plate with an average equiaxed grain size of about $30 \mu \mathrm{m}$. The magnesium alloy is commercial $\mathrm{Mg}-\mathrm{Al}-\mathrm{Zn}$ alloy with chemical composition: Mg-3.28Al-1Zn-0.44Mn (all in wt.\%, balance $\mathrm{Mg}$ ) and grain size of about $16 \mu \mathrm{m}$. The as-received CG materials are then processed by equal channel anglar pressing (ECAP) method through $\mathrm{Bc}$ route to reduce their grain sizes (12-13). The details in materials fabrication are given elsewhere (14-15). Microstructures of the materials before and after processing are shown in Fig. 1 and Fig. 2. Clearly, the grain sizes are greatly reduced for both of the two kind of materials. Most of the grains of the ECAP-processed Ti are between $400 \mathrm{~nm}$ to $800 \mathrm{~nm}$ and the average grain size is about $500 \mathrm{~nm}$, which falls in the range of UFG category.

This is an Open Access article distributed under the terms of the Creative Commons Attribution License 4.0, which permits unrestricted use, distribution, and reproduction in any medium, provided the original work is properly cited. 


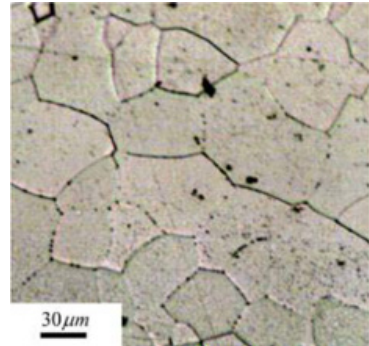

(a)

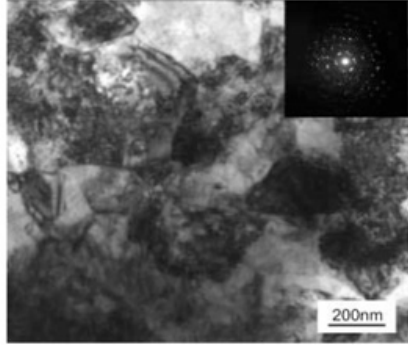

(b)
Figure 1. The optical photographs of pure Ti. (a) as-received, (b) after ECAP. The average grain sizes were determined though lineal intercept procedure to be 30 and $0.5 \mu \mathrm{m}$, respectively.

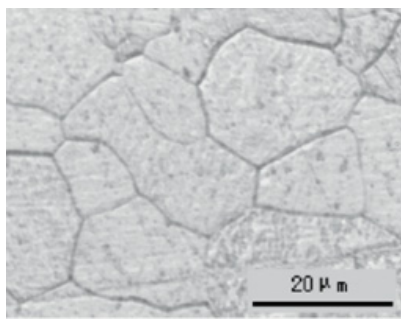

(a)

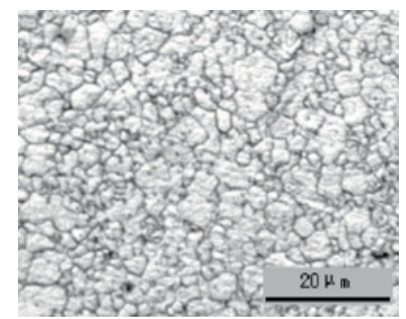

(b)
Figure 2. The optical photographs of $\mathrm{AZ} 31 \mathrm{Mg}$ alloy. (a) as-received, (b) after ECAP. The average grain sizes were determined though lineal intercept procedure to be 16 and $1.7 \mu \mathrm{m}$, respectively.

The average grain size of ECAP-processed AZ31 is about $1.75 \mu \mathrm{m}$. The relatively larger grain is a result of the warm ECAP process.

\subsection{Mechanical testing}

Cylinderical specimens with dimension of $\varnothing 4 \mathrm{~mm} \times 4 \mathrm{~mm}$ were prepared along the rolling/extrusion direction. The quasi-static uniaxial compressive experiments were carried out at room temperature on a servohydraulic testing machine and a extensometer was equipped to measure the deformation. The strain rate for all of the quasi-static tests are controlled to be $10^{-3} \mathrm{~s}^{-1}$. The dynamic testing were conducted via a split hopkinson pressure bar system at strain rates from $1500 \mathrm{~s}^{-1}$ to $1800 \mathrm{~s}^{-1}$. The strain-control during high strain rate testing is achieved by using stoprings.

\section{Results and discussion}

Post-observation on the dynamically loaded specimens indicates that both the CG and UFG AZ31 are fractured due to adiabatic shear, shown in Fig. 3 as an example. The UFG Ti does not fracture under quasi-static compression in our tests (maximum strain 0.6), while adiabatic shear localization is observed in the specimen after high strain rate loading, shown in Fig. 4. The vein pattern on the fracture surface indicates material flow and adiabatic nature of the failure process. Since there is no apparent fracture in CG Ti under static or dynamic loading, these test results are not listed in this work.

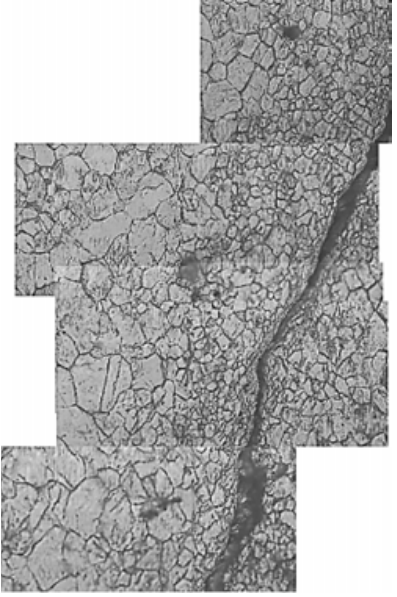

Figure 3. Representative dynamic compressive fracture mode of AZ31 alloy (CG).
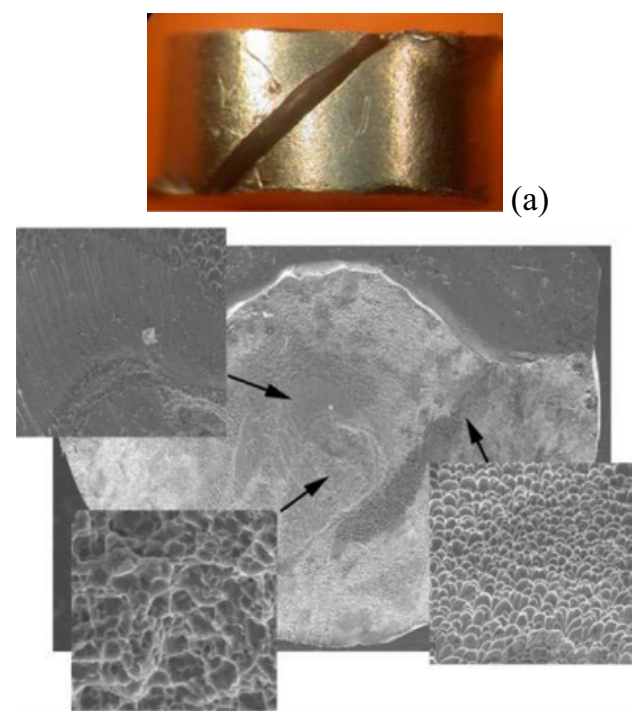

(b)

Figure 4. Representative compressive fractography of UFG Ti deformed at room temperature with strain rate $1500 \mathrm{~s}^{-1}$. (a) Shear fracture, (b) fractography of the shear plane.

\subsection{Mechanical properties of UFG titanium}

The UFG Ti were loaded by combined static and dynamic loadings. Figure 5 displays the stress-strain curves of this material. Most of the specimens were loaded twice, either static loading followed by dynamic loading (Fig. 5 (a)) or dynamic loading followed by dynamic loading (Fig. 5 (b)), with curves of single loaded (static or dynamic) specimens for comparison. The charaters "S" and "D" within the icons of Fig. 5 indicate "Static" and "Dynamic", respectively. For example, "UFG6-S-D" denotes sample "UFG6" was firstly loaded statically to a certain strain (about 10\% here) and then loaded dynamically until it was fractured. "UFG16-D-D-D" indicates sample "UFG16" was loaded three times at high strain rates $\left(1500 \mathrm{~s}^{-1} \sim\right.$ $\left.1800 \mathrm{~s}^{1}\right)$. These two or three parts of the stress strain curves of one specimen are displaced with the same icon. The sharp increase of the curves in Fig. 5(b) is not the intrinsic behavior of the material but due to the contact of the stop-ring with the loading bars of SHPB. The arrows 


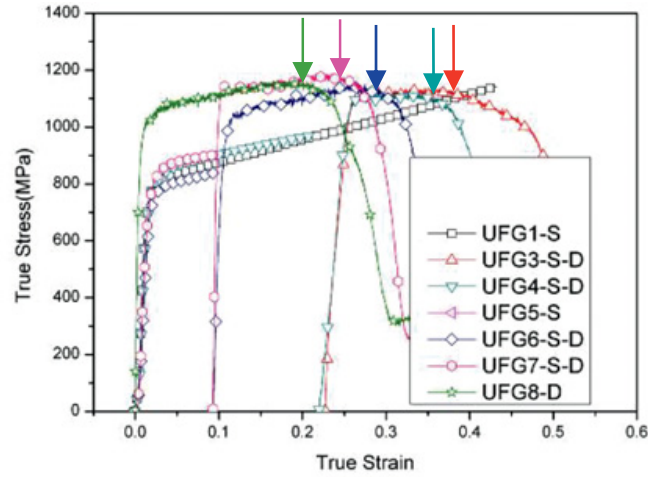

(a)

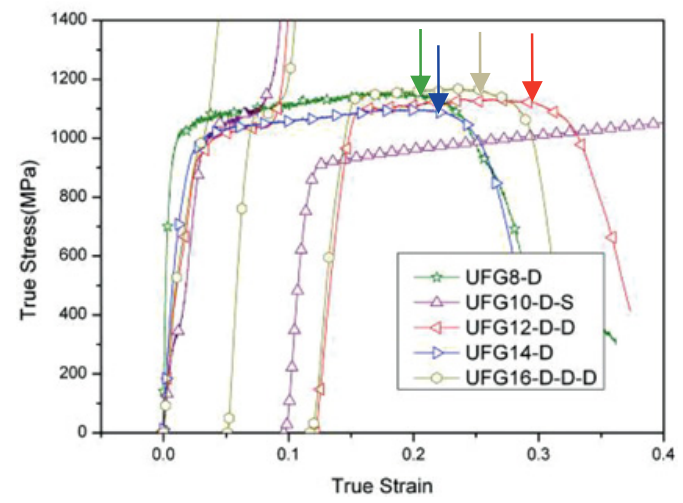

(b)

Figure 5. Mechanical behavior of UFG Ti under combined static and dynamic loading. (a) static loading followed by dynamic loading, (b) dynamic loading followed by dynamic loading. "S" and "D" indicate "Static" and "Dynamic", respectively. The abrupt rising up of the curves in (b) is not the intrinsic behavior of the material but due to the effect of stop-ring.

within the figure point out the strain where stress begin to fall.

Clearly, the fracture strain (or the critical strain for ASB initiation) of UFG $\mathrm{Ti}$ is not a constant but highly dependent on the loading history. Similar with the experimental results of Rittel et al. (10), the critical strain increases with increasing pre-strain caused by static loading, as shown in Fig. 5(a). The two-step or three-step dynamic loading also affects the failure strain, which is different from results of other researchers $(10,16-17)$. It should be noted that static loading itself did not lead to any catastrophic failure of UFG Ti. Moreover, we did not find any shear localization or crack within the specimen that experienced $10 \%$ dynamically pre-loaded stain and following static loading (specimen UFG10-D-S in Fig. 5(b)). In addition, the strain rate effect on mechanical properties of UFG Ti is significant. The yield stress of the material increases from $700 \mathrm{MPa}$ at strain rate $0.001 / \mathrm{s}$ to $1000 \mathrm{MPa}$ at $1500 / \mathrm{s}$.

To investigate the fracture behavior of UFG $\mathrm{Ti}$ quantitatively, the total fracture strain and contributions from static and dynamic loadings are sumarried in Table 1. The initiation of ASB under single dynamic loading is around 0.2 uniaxial compressive strain. The static pre-loading before dynamic compression increases the total fracture strain. Moreover, as the static strain increases, the total strain increases accordingly. However,
Table 1. Fracture strain of UFG Ti.

\begin{tabular}{|l|l|l|c|c|}
\hline No. & $\begin{array}{l}\text { Loading } \\
\text { history }\end{array}$ & $\begin{array}{c}\text { Static } \\
\text { strain }\end{array}$ & $\begin{array}{c}\text { Dynamic } \\
\text { strain }\end{array}$ & $\begin{array}{c}\text { Total fracture } \\
\text { strain }\end{array}$ \\
\hline UFG1 & $\mathrm{S}$ & 0.43 & 0 & $\begin{array}{c}\text { No apparent } \\
\text { fracture }\end{array}$ \\
\hline UFG3 & $\mathrm{S} \sim \mathrm{D}$ & 0.23 & 0.13 & 0.36 \\
\hline UFG4 & $\mathrm{S} \sim \mathrm{D}$ & 0.22 & 0.12 & 0.34 \\
\hline UFG6 & $\mathrm{S} \sim \mathrm{D}$ & 0.09 & 0.18 & 0.27 \\
\hline UFG7 & $\mathrm{S} \sim \mathrm{D}$ & 0.09 & 0.14 & 0.23 \\
\hline UFG8 & $\mathrm{D}$ & 0 & 0.20 & 0.20 \\
\hline UFG14 & $\mathrm{D}$ & 0 & 0.21 & 0.21 \\
\hline UFG10 & $\mathrm{D} \sim \mathrm{S}$ & 0.57 & 0.10 & $\begin{array}{c}\text { No apparent } \\
\text { fracture }\end{array}$ \\
\hline UFG12 & $\mathrm{D} \sim \mathrm{D}$ & 0 & $0.12+0.14$ & 0.26 \\
\hline UFG16 & $\mathrm{D} \sim \mathrm{D} \sim \mathrm{D}$ & 0 & $0.05+0.06+$ & 0.23 \\
& & & 0.12 & \\
\hline
\end{tabular}

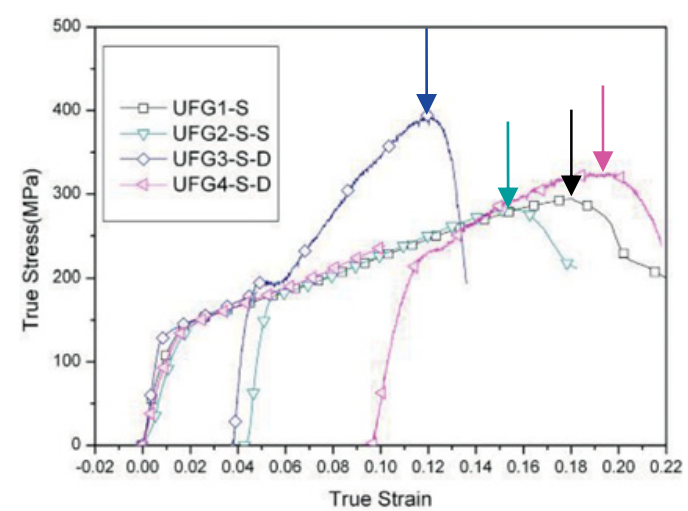

(a)

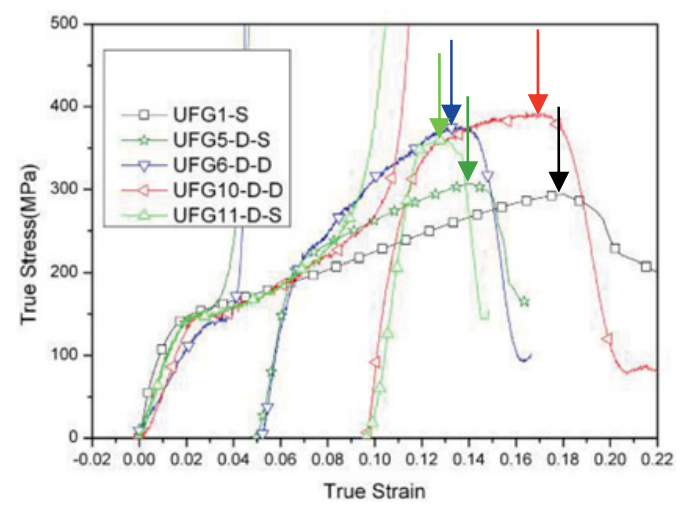

(b)

Figure 6. Mechanical behavior of UFG AZ31 alloy under combined static and dynamic loading. (a) static loading followed by dynamic loading, (b) dynamic loading followed by dynamic loading. "S" and "D" indicate "Static" and "Dynamic", respectively. The abrupt rising up of the curves in (b) is not the intrinsic behavior of the material but due to the effect of stop-ring.

the static loading process makes contribution to the final failure of the material. Larger static strain results in smaller dynamic strain in the deformation process of one specimen. Two-step or three-step dynamic loading affects the final ASB initiation strain too, although it is not so apparent as the static pre-loading.

\subsection{Mechanical properties of UFG AZ31}

Similar experiments were conducted on UFG AZ31 magnsium alloy. The stress strain curves are displayed in 
Table 2. Fracture strain of UFG AZ31.

\begin{tabular}{|l|l|c|c|c|}
\hline No & $\begin{array}{l}\text { Loading } \\
\text { history }\end{array}$ & $\begin{array}{c}\text { Static } \\
\text { Strain }\end{array}$ & $\begin{array}{c}\text { Dynamic } \\
\text { Strain }\end{array}$ & $\begin{array}{c}\text { Total Fracture } \\
\text { Strain }\end{array}$ \\
\hline 1 & S & 0.18 & 0 & 0.18 \\
\hline 2 & $\mathrm{~S} \sim \mathrm{S}$ & $0.04+0.11$ & 0 & 0.15 \\
\hline 3 & $\mathrm{~S} \sim \mathrm{D}$ & 0.04 & 0.08 & 0.12 \\
\hline 4 & $\mathrm{~S} \sim \mathrm{D}$ & 0.10 & 0.10 & 0.20 \\
\hline 5 & $\mathrm{D} \sim \mathrm{S}$ & 0.09 & 0.05 & 0.14 \\
\hline 11 & $\mathrm{D} \sim \mathrm{S}$ & 0.03 & 0.10 & 0.13 \\
\hline 6 & $\mathrm{D} \sim \mathrm{D}$ & 0 & $0.05+0.09$ & 0.14 \\
\hline 10 & $\mathrm{D} \sim \mathrm{D}$ & 0 & $0.10+0.07$ & 0.17 \\
\hline
\end{tabular}

Fig. 6. Different from pure Ti, AZ31 Mg alloy fractures even under quasi-static loading. Obviously, the failure strains of specimens with different loading history differ a lot. The static pre-loading postpones the initiation of ASB and increases the total fracture strain. What's intresting is that the dynamic pre-loading has similar effect on the total fracture strain with that of static preloading. The contributions of static and dynamic loadings are summaried in Table 2. Although the experimental results seem to be irregular, one definite fact is that the contribution of dynamic strain to fracture of the sample is not a constant. The overall trend is that the dynamic part decreases with increasing static strain of pre-loading.

\subsection{Mechanical properties of CG AZ31}

Figure 7 presents the stress-strain curves of CGAZ31 under different loading process. The arrows within the figure point out the fracture strain, or initiation of shear localization. Different from Fig. 5 and Fig. 6, these arrows in Fig. 7 are rather concentrated, demonstrating the loading history has little effect on the final fracture strain. As shown in Fig. 7(a), a static pre-loading of $10 \%$ does not result in significant increase in total failure strain. The quantitative data of CG AZ31 are listed in Table 3. The fracture strain at static loading is identical with that at dynamic loading, indicating that the contribution of static loading is quantitatively similar with that of dynamic, even though they may lead to different deformation and failure mechanisms. The combined static $\sim$ static, static $\sim$ dynamic, dynamic $\sim$ static or dynamic $\sim$ dynamic loadings did not change this characteristic greatly. In this case, critical strain seems to be a good criterion for evaluating the formation of ASB.

\subsection{Criterion on the deformation localization}

Traditionally, most of the researchers take critical shear strain as a criterion of shear localization (or in dynamic case, ASB formation). Our experimental results indicate that this strain-based criterion could not describe precisely the fracture behavior of UFG pure Ti or AZ31. The fracture strain is highly related to the loading history.

For UFG pure $\mathrm{Ti}$, which has comparatively good ductility under compression, the static deformation part plays a relatively small role in the initiation of ASB, yet it could not be ignored. The failure strain is about 0.21 under single dynamic loading. Take this value as a
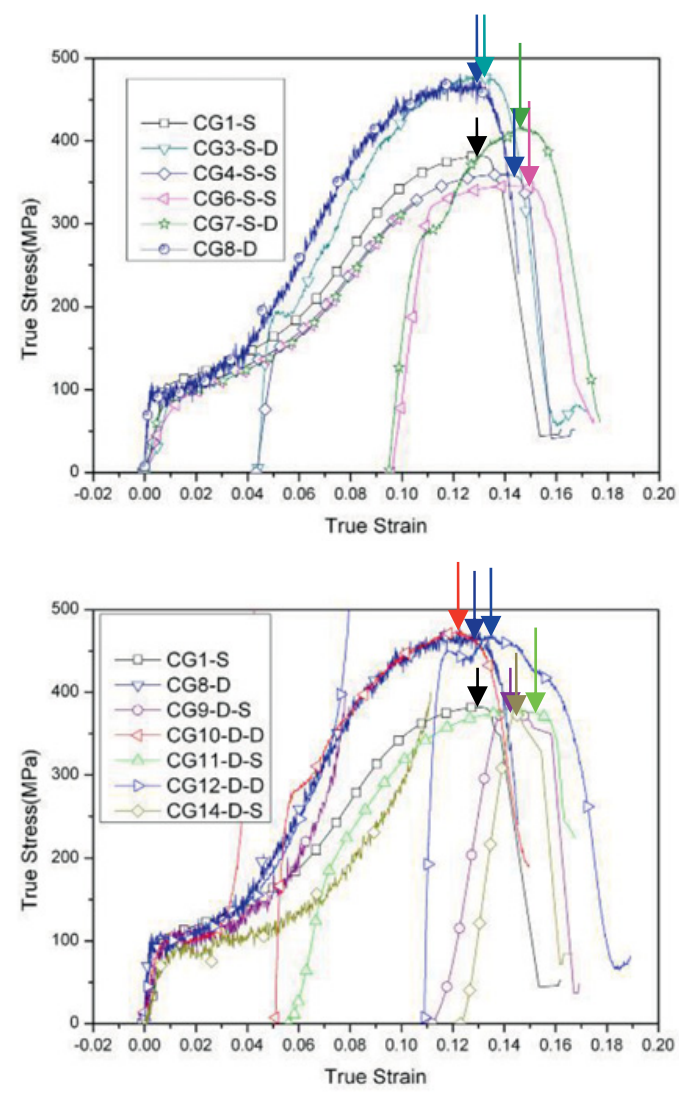

(a)

Figure 7. Mechanical behavior of CG AZ31 alloy under combined static and dynamic loading. (a) static loading followed by dynamic/static loading, (b) dynamic loading followed by dynamic/static loading. "S" and "D" indicate "Static" and "Dynamic", respectively. The abrupt rising up of the curves in (b) is not the intrinsic behavior of the material but due to the effect of stop-ring.

reference, the static strain could be converted to dynamic strain and the coefficient is about 0.4. The increase of total strain in the interrupted dynamic tests is probably due to the interruption of the heat accumulation within a specimen during dynamic loading. Dynamic stored energy is defined as the energy stored in the material by dynamic loading and could be calculated by integrating the stressstrain curve.The contribution of dynamic stored energy has identical trend with the dynamic strain in a failure process, thus it is not appropriate to use dynamic stored energy as a criterion for ASB formation for UFG Ti. The overall trend is similar for UFG AZ31 with UFG Ti, but the contribution of static loading to final failure is larger and comparable with that of dynamic loading. In that case, the strain-based criterion appears better than the criterion base on dyamic stored energy for UFG AZ31, but still the strain-based criterion could not describe the fractrue point accurately.

As to the CG AZ31, most of the failure strains are within $0.13 \sim 0.15$ regardless of the loading process. The contribution of static strain in a failure process is identical with that of dynamic strain. Taking strain as the criterion for initiation of shear localization (ASB for dynamic case) is ideal for CG AZ31. The dynamic stored energy-based 
Table 3. Fracture strain of CG AZ31.

\begin{tabular}{|l|l|c|c|c|}
\hline No. & $\begin{array}{l}\text { Loading } \\
\text { history }\end{array}$ & $\begin{array}{c}\text { Static } \\
\text { Strain }\end{array}$ & $\begin{array}{c}\text { Dynamic } \\
\text { Strain }\end{array}$ & $\begin{array}{c}\text { Total Fracture } \\
\text { Strain }\end{array}$ \\
\hline CG1 & S & 0.13 & 0 & 0.13 \\
\hline CG4 & $\mathrm{S} \sim \mathrm{S}$ & $0.04+0.10$ & 0 & 0.14 \\
\hline CG6 & $\mathrm{S} \sim \mathrm{S}$ & $0.10+0.05$ & 0 & 0.15 \\
\hline CG7 & $\mathrm{S} \sim \mathrm{D}$ & 0.10 & 0.05 & 0.15 \\
\hline CG3 & $\mathrm{S} \sim \mathrm{D}$ & 0.04 & 0.09 & 0.13 \\
\hline CG8 & $\mathrm{D}$ & 0 & 0.13 & 0.13 \\
\hline CG9 & $\mathrm{D} \sim \mathrm{S}$ & 0.03 & 0.11 & 0.14 \\
\hline CG11 & $\mathrm{D} \sim \mathrm{S}$ & 0.09 & 0.06 & 0.15 \\
\hline CG14 & $\mathrm{D} \sim \mathrm{S}$ & 0.02 & 0.12 & 0.14 \\
\hline CG10 & $\mathrm{D} \sim \mathrm{D}$ & 0 & $0.05+0.07$ & 0.12 \\
\hline CG12 & $\mathrm{D} \sim \mathrm{D}$ & 0 & $0.11+0.03$ & 0.14 \\
\hline
\end{tabular}

criterion is only related to the dynamic strain part, thus it is not applicable to this material.

\section{Summary and conclusion}

In this work, we evaluated two kind criterions for ASB formation, i.e. the strain-based criterion and dynamic stored energy-based criterion, on UFG materials as well as CG metals. The main conculsions are summaried in the following:

1. Neither strain-based nor dynamic stored energybased criterion could describe accurately the failure behavior of UFG Ti or UFG AZ31 magnisium alloy.

2. Failure of the UFG materials is related to both static loading process and dynamic loading process. However, the contributions of the two processes are different and material dependent.

3. The strain-based criterion can describe the failure of CG AZ31 well regardless of loading history, indicating static loading has similar effect in ASB formation with dynamic loading.

Our experimental results demonstrate that the effects of loading history on ASB formation may be different for different materials. The dynamic stored energy is not a quantity for general application in evaluating shear failure, neither is the shear strain. Converting results of static loading to dynamic might be a feasible way to construct a general criterion, but the intrinsic relationship and microstructure-based mechanism need further investigating.

The authors would like to thank the financial support by the National Natural ScienceFoundation of China (Contract nos. 11472227 and 11102166), the 111 Project (Contract no. B07050), and the Fundamental Research Funds for the Central Universities (No.310201401JCQ01001).

\section{References}

[1] M. A. Meyers, A. Mishra, D. J. Benson, Progress in Materials Science 51, 427 (May, 2006).

[2] Y. M. Wang, M. W. Chen, F. H. Zhou, E. Ma, Nature 419, 912 (Oct. 2002).

[3] T. H. Fang, W. L. Li, N. R. Tao, K. Lu, Science 331, 1587 (March 25, 2011, 2011).

[4] Y. T. Zhu, X. Z. Liao, Nature Materials 3, 351 (2004).

[5] Y. L. Bai, Journal of the Mechanics and Physics of Solids 30, 195 (1982).

[6] T. W. Wright, The physics and mathematics of adiabatic shear bands. (Cambridge University Press, Cambridge, New York, Port Melbourne, Madrid, Cape Town, 2002).

[7] Y. B. Xu, J. H. Zhang, Y. L. Bai, M. A. Meyers, Metall. Mater. Trans. A-Phys. Metall. Mater. Sci. 39A, 811 (Apr. 2008).

[8] Q. Wei, Journal of Material Science 42, 1709 (2007).

[9] Q. Wei et al., Acta Materialia 52, 1859 (Apr. 2004).

[10] D. Rittel, Z. G. Wang, M. Merzer, Physical Review Letters 96, 075502 (2006).

[11] D. Rittel, P. Landau, A. Venkert, Physical Review Letters 101, 165501 (2008).

[12] T. Suo, Y. Li, Y. Guo, Y. Liu, Materials Science and Engineering A 432, 269 (2006).

[13] T. Suo et al., Mechanics of Materials 43, 111 (2011).

[14] X. Sun, Y. Guo, Y. Li, Unpublished work (2015).

[15] X. Yu, Y. Li, Y. Guo, Unpublished work (2015).

[16] D. Rittel, S. Osovski, International Journal of Fracture 162, 177 (2010/03/01, 2010).

[17] J. A. Rodríguez-Martínez, G. Vadillo, D. Rittel, R. Zaera, J. Fernández-Sáez, Mechanics of Materials 81, 41 (2015). 